\title{
CARACTERIZAÇÃO DE FRUTOS DE UVAIA COLETADOS EM DIFERENTES LOCALIDADES DA REGIÃO SERRANA DO ESPÍRITO SANTO
}

\author{
Lorena Abdalla de O. Prata Guimarães ${ }^{1}$ \\ Guilherme Carneiro de Mendonça ${ }^{2}$ \\ André Angelo Bellon ${ }^{3}$ \\ Raiza Rainha Dorzenoni ${ }^{4}$ \\ Tiago de Oliveira Godinho ${ }^{5}$
}

\begin{abstract}
Resumo: A uvaia (Eugenia pyriformis) tem grande potencial para uso na dieta alimentar. Para ampliar o conhecimento sobre frutíferas nativas não tradicionais, este trabalho objetivou caracterizar frutos de uvaia coletados em quatro localidades da região serrana do ES - Venda Nova do Imigrante (L1), Marechal Floriano (L2) e Domingos Martins (L3 e L4). Foram avaliadas a relação comprimento/diâmetro, rendimento da polpa, massa dos frutos inteiros e sem sementes, sólidos solúveis totais (SST), pH, acidez titulável (AT), vitamina C e "ratio" (SST/AT). Os frutos das diferentes localidades têm grande variabilidade nas características químicas e morfométricas. Os maiores frutos foram os obtidos na localidade de Vitor Hugo (L2). A polpa dos frutos obtidos em L2 e na localidade de São João de Viçosa (L1) tiveram, em geral, características químicas mais desejáveis. Por serem os frutos muito saborosos, com teores de vitamina C elevados e por serem suas potencialidades pouco exploradas, a espécie merece e precisa ser amplamente estudada e cultivada.
\end{abstract}

Palavras-chave: Eugenia pyriformis; Frutas nativas; Produtos florestais não madeireiros; Vitamina C.

\footnotetext{
${ }^{1}$ Incaper/CRDR Centro Serrano, Brasil. E-mail: Iorena.prata@hotmail.com.

${ }^{2}$ lema/Programa Reflorestar, Brasil. E-mail: guic_m@yahoo.com.br.

3 Incaper/CRDR Centro Serrano, Brasil. E-mail: aa-bellon@hotmail.com.

${ }^{4}$ Incaper/CRDR Centro Serrano, Brasil. E-mail: raiza_rainha_vni@hotmail.com.

${ }^{5}$ Incaper/CRDR Centro Serrano, Brasil. E-mail: godinhoto@h̄otmail.com.
} 